\title{
A composite index model for evaluating used equipment
}

\author{
C.O. Anyaeche, and E. B. Omoniyi \\ 1,2 Department of Industrial and Production Engineering, University of Ibadan, Ibadan, Nigeria
}

\begin{abstract}
For many developing countries the importation of second-hand goods including used vehicles accounts for a large proportion of all machinery imports which sometimes shows double-digit rates of growth. However, there appears not to be a corresponding level of awareness on quality of the items and the techniques for assessing products/items appear not analytic. It is buy as seen. This work is an attempt to develop a framework to bridge this gap in knowledge. This work developed a composite index model for vehicle assessment. The performance of some used vehicles were determined and then compared with the performance of the benchmark.

Data were collected from different vehicle types. The model was applied to three vehicle types A, B and C. For body exterior, the results are $0.563,0.879$ and 0.484 for $\mathrm{A}, \mathrm{B}$ and $\mathrm{C}$ respectively, while engine performance gave $0.789,0.766$ and 0.759 for $\mathrm{A}, \mathrm{B}$ and $\mathrm{C}$ respectively. The overall indices are $0.890,0.7148$ and 0.5414. and the results showed B has a better preference than A and then C.

Appling this model would help a prospective buyer of a used vehicle to use an analytical approach in the intended purchase, and thus good value for money .
\end{abstract}

Keywords: - Composite index, Used equipment, Model.

\subsection{Background information}

\section{INTRODUCTION}

For many developing countries and emerging markets the importation of second-hand goods accounts for a large proportion of all machinery imports. The transfer of second-hand machinery and equipment sometimes shows double-digit rates of growth. Second-hand machinery and equipment to the value of more than 100 billion US dollars are sold every year, primarily to the developing countries and emerging markets (Jorg et al., 2003, Ghose A, 2005). This figure is substantially higher if exports in the context of foreign investments are also considered.

The international trade of used vehicles reveals a similar picture. In view of rising environmental standards in the countries of origin and the active interest of consumers in developing countries and emerging markets, trade continues to thrive (Hendel and Lizzeri, 1999, Emons, and Sheldon 2002). Turnover from second-hand vehicles has a value of approximately 50 billion US dollar annually. A large proportion of it goes to developing countries and emerging markets. According to Jorg et al. (2003); almost 500,000 second-hand vehicles with a unit price of less than $€ 2,500$ and an average age of 6-8 years originate from Germany alone. These vehicles are mainly sold to countries in Eastern Europe and Africa.

The reasons for the rapidly growing interest in trading in second-hand machinery and equipment are complex. Structural changes, increasingly shorter investment cycles, more stringent environmental standards and product requirements as well as corporate bankruptcies are among the factors in the industrialized countries while progressing globalization, better communication and information media, increased privatization, improved means of transport and local economic growth in the countries of destination are the factors in developing economies. There are also the issues of the failed automobile assembly plants in these countries which many have traced to ownership structure, (Anyaeche, 2007).

Evaluation of vehicles is mostly qualitative in nature (Anyaeche, 2007). It was discovered that qualitative indices alone are not sufficient for evaluation. The reasons adduced for these are that many of these indices are considered to be either too technical or difficult to evaluate, thus, evaluation is mostly left to the discretion of local automobile dealers or technicians who mostly base their evaluations on their experience and trial by error method. Sometimes, they might carry out some minor visual inspections based on their knowledge and the tools available to them, but this method has proved not to be reliable especially with new generation vehicles most of which use "mecatronics technology".

Also, there appears to be no corresponding level of awareness and analytical method of assessing these vehicles. Customers appear to adopt just buy as seen. This work is an attempt to address this gap, by developing a simple analytical method for assessing used vehicles

\subsection{Objectives}

The objectives of this study are to 
1. Develop a composite index model for evaluating used vehicles.

2. Carryout an evaluation of some second-hand vehicles using the developed composite index model.

\section{EVALUATION TECHNIQUES}

A composite index is constructed with an objective to obtain a synoptic or comprehensive single number, representing a vast array of measurements on the multiple aspects of a 'conceptual entity' such as general price level, cost of living, level of economic development (Mishra and Nardo, 2005). It also includes quality of life, human development and status of social well being. An index is a statistical device for indicating the relative movement of data where measurement of actual movements is difficult or incapable of being made. Some of the list of advantages of composite indices (Mishra, 2007) may be presented as follows:

- The simplicity of a composite index facilitates necessary negotiations about its practical value and usefulness.

- Reduce transaction costs of negotiations with such indicators increase the latter's efficiency and effectiveness, probably leading to the development of better policies and programs.

- They provide a means of comparing diverse phenomena and assessing their relative importance, status or standing on the basis of some common scale of measurement, across time.

Such composite indices are often a weighted linear combination of a host of variables that may be symbolically expressed as $I=W X$, where $X$ is an $n \times m$ matrix of measurements in $n$ rows (cases) and $m$ columns (variables), $W$ is a column vector of $m$ elements and therefore, $I$ is a column vector of $n$ index values, one for each case summarizing all variables for the case concerned. Alternatively, it may be specifically expressed for vehicles as:

$$
\begin{aligned}
& I=\sum_{i=1}^{n} w_{i} x_{i}=w_{1} x_{1}+w_{2} x_{2}+w_{3} x_{3}+w_{4} x_{4}+w_{5} x_{5} \ldots+w_{n} x_{n} \\
& I=\sum_{i=1}^{n} \sum_{j=1}^{m} w_{i j} x_{i j}=w_{11} x_{11}+w_{12} x_{12}+w_{13} x_{13}+w_{14} x 1_{4}+w_{15} x_{15} \ldots+w_{i m} x_{i m} \\
& \text { Where } i=1,2 \ldots \mathrm{n} \\
& \quad j=1,2 \ldots \mathrm{m}
\end{aligned}
$$

$I=$ total vehicle index.

$I_{i}=$ vehicle sectional index

There are two approaches to determining $W$ or weights; first by assessing the importance of different variables with regard to the entity, idea or concept that they measure (Munda and Nardo, 2005) and secondly by obtaining those weight intrinsically. In the first case the weights are obtained from extraneous information. They might be based on the expert opinion or some other Mathematical model from the data $X$ itself.

According to Mishra (2007), the Principal Components Analysis (PCA) is perhaps the most-used method to obtain weights intrinsically. The PCA determines weights of different variables such that the sum of the squared coefficients of correlation between the index (I) and the variables (X) is maximized.

Mathematically, an index is constructed with reference to a base value and therefore the above equation (2) only evaluates a component relative to its intrinsic characteristics that is assumed as quality of the component. We use the PCA in this work.

In this work, the base value is the new vehicle. It is assumed that a new vehicle has met the entire required standard before the manufacturer can sell it and also, the factor that gave rise to the phrase "used vehicle" is from the new vehicle due to depreciation in its value. Simple Aggregate Method can therefore be applied using Weighted Aggregate Method, and taking the base value as the corresponding parameter evaluated in the used vehicle.

We thus express the index in line with above discourse as:

$$
I=\frac{\sum W_{i}}{\sum W}
$$

This work uses this equation (3) for the evaluation of the indices.

\section{APPLICATION}

\subsection{Composite sections}

In this work, composite items are those parts of the vehicle that a prospective customer of automobile checks and tries to evaluate when purchasing a used vehicle. They are grouped according to vehicle distinct parts using various manufacturers' and dealers' checklists e.g. Toyota checklist (Toyota, 2009; Omoniyi, 2009; NAMA, 2013). The following are the major checkpoints (TUV Reliability Report, 2013) and they are further amplified into various unit components. 
Body exterior evaluation:- Chassis, Bumper and Fascia, Doors, Hood, Roof rack and Trim, Windshield, Side and Rear windows, Mirrors and Wipers.

Exterior light:- Head light, Tail lights, Brake lights, Parking lights, Hazard lights, Reverse lights, Turn signal and marker lights.

Interior Amenities:- Radio and Speaker, Antenna, Clock, Horn, Ash tray, Lighter, Glove box and Centre arm rest, Steering wheel lock, Mirrors, Instrument panel, Light and Warning light indicators, Fuel filler, Door release and Interior door handle.

Interior Condition and Appearance:- Carpet and Floor mats, Door trim and panels, Headliner and Sun visors, Seat upholstery, Door locks and control, Child safety locks, Windows and Controls.

Engine:- Fluid leakages, Oil in air cleaner, Cylinder compression reading through gauge, Timing belt, Fluids, Belts, Hoses, Engine mountain, Radiator, Cooling fan and Fan motor, Water pump noise, Fuel lines and hoses, Starter operation and Cranking, Alternator battery, Fuel economy and Engine capacity.

Emission:- Catalytic converter and shielding, Emission control test, nature and type of smoke coming from exhaust pipe, Oil in exhaust pipe mouth early and late start.

Tyre :- Correct Tyre size, Tread depth measurement using gauge, Condition and Abnormal wear, all the Tyre match, Spare Wheel condition.

Suspension and Steering:- Alignment, Fluid, Steering linkages, Power steering pump and hoses, control arm and all joints, Tie rods and Idler arm, Springs.

Braking System:- Calipers and Cylinders, Pad And Shoes, Rotor And Drums, Brake System Lines and Hydraulic, Parking Brakes, Anti-Lock Braking System (ABS), Electronic Brake Force Distribution (EBD) and Adaptive Cruise Control (ACC).

Dash Board:- Electronic Control Unit (ECU), Fuel Gauge, Speedometer, Tachometer, Odometer, Seat Belt Warning Light and Air Bag, Engine Malfunctioning Light, and Automotive Navigation System.

Safety:- Seat Belts, Air Bags, Alarm and Theft deterrent System.

Road test:- Engine starting cold and hot, Engine idle quality, Engine performance and smooth acceleration, Engine noise, Automatic transmission and Transaxle noise, Shift interlock, Drive axle and Transfer case bearing or Gear vibration, Clutch operation, Steering linkage performance, Brakes operations, Cruise control operation, Dash board operation, Body and suspension during rough road test.

\subsection{Composite index of sections}

To determine index for each section of the vehicle, equation (2) will be applied.

In Body evaluation, we consider the following:

1.Frame

3. Bumper/Fascia

5. Hood

7. Windshield

9. Mirrors

Applying equation (2)
2. Body panel

4. Door

6. Roof rack

8. Side/Rear windows

10. Wipers

$$
I_{i}=\sum_{i=1}^{n} \sum_{j=1}^{m} w_{i j} x_{i j}=w_{11} x_{11}+w_{12} x_{12}+w_{13} x_{13}+w_{14} x_{14}+w_{15} x_{\cdot_{15} . .}+w_{110} x_{110}
$$

Similar evaluation were done for other parts of the vehicle and the values obtained. The weight (W) for each of the section and sub sections can be evaluated in terms of relative importance to the section. The costs of the components were also obtained from dealers (Omoniyi, 2009).

IV. RESULTS AND DISCUSSION

Table 1: Vehicle Evaluation Results

\begin{tabular}{|l|l|l|l|}
\hline \multicolumn{1}{|c|}{ Item Examined } & \multicolumn{3}{c|}{ Vehicle Types } \\
\hline Body exterior evaluation & A & B & C \\
\hline Exterior light evaluation & 0.563 & 0.879 & 0.484 \\
\hline Interior Amenities evaluation & 0.749 & 0.880 & 0.616 \\
\hline Engine evaluation & 0.633 & 0.834 & 0.454 \\
\hline Tyre evaluation & 0.789 & 0.766 & 0.759 \\
\hline Suspension and Steering evaluation & 0.600 & 0.700 & 0.450 \\
\hline Braking system evaluation & 0.693 & 1.000 & 0.282 \\
\hline Dash board evaluation & 0.750 & 0.900 & 0.750 \\
\hline Overall vehicle index & 0.750 & 0.750 & 0.250 \\
\hline
\end{tabular}


From Table 1, evaluation of Vehicle A, body exterior evaluation index was 0.879, exterior light was 0.880 , Interior amenities was 0.834 , Engine was 0.766 , Engine mechanical test equal to 1.00 which actually means that the engine was working perfectly. Tyre index was 0.70 which indicate that the tyre had been used but was still within the safety limit. Suspension and steering were also in good form with an index of 1.00. Braking system index was 0.90 which is high. Dash board index was 0.75 . The overall vehicle index was evaluated to be 0.889 .

Evaluation from Vehicle B gives the body exterior index as 0.563 which is just above average and implies that quality. Exterior light index was 0.79. Interior amenities index was evaluated to be 0.633 . The Engine index was found to be 0.789; Engine mechanical test index was 1.00 which implies that the engine does not have any internal/combustion problem. Tyre index was 0.60 , suspension and steering index was 0.693 , braking system was 0.75, Dash board index was 0.75 and overall vehicle evaluation was 0.7148 .

For Vehicle C, body exterior evaluation index was 0.484 , this implies that the appearance of the body is not attractive and the reliability and quality might likely be low. Exterior light was 0.616 and Interior amenities index was 0.454. Engine index was 0.759 while the engine mechanical test was 1.00.Tyre index was 0.45 , Suspension and steering was bad with an index of 0.282 . Braking system was also evaluated to be 0.251 . The overall vehicle index was evaluated to be 0.5414 .

From the evaluation, the vehicle A was evaluated to have the highest index. The closer to the bench mark the value of new automobile is, the better the reliability since a new automobile is assumed to be of high quality and reliability. Vehicle B has an index that is also acceptable under evaluation of used vehicle. But Vehicle $\mathrm{C}$ can be said to be reliable due to the fact the index is just above average even though is also a used vehicle. The farther the index from the bench mark the lower the quality and reliability.

\section{CONCLUSION}

The study has developed a composite index for evaluating used vehicles, determine indices used in second-hand vehicles assessment, their relative importance to the vehicle assessment, and the evaluation of second-hand vehicles, using developed composite index.

Vehicle component parts were identified and their relative weights determined. Three vehicles were used for evaluations, each was divided into components (body exterior, exterior light, interior amenities, interior condition and appearance, engine, tyre, suspension and steering, braking system, dash board, road test, and safety), and the composite index for each section was determined. Based on the components used in the evaluation the first vehicle has an average index of 0.89 in all the indices, the second with an index of 0.71 and the third vehicle 0.54 which could be said to be just of average reliability.

This work developed a composite index model for evaluating used vehicle marketing. This would provide an analytic framework for assessing used vehicles instead of the common practice of using qualitative method of evaluation. This would ensure that customers and other stakeholders have good value for their money.

\section{REFERENCES}

[1] Jorg Janischweski, Mikael P. Henzler and W. Kahlenborn. 2003. The Export of Second-hand Goods and the transfer of Technology.www.nachhaltigkeitsrat.de May 2007. Anindya Ghose . 2005. Used Good Trade Patterns: A Cross-Country Comparison of Electronic Secondary Markets, Stern School of Business, NYU

[2] Hendel, I. and Lizzeri 1999. Adverse Selection in Durable Goods Markets. American Information Search for Automobiles. Journal of Marketing Research 40(2), pp 193-209.

[3] Emons, W. and Sheldon G. 2002.The Market for Used Cars: A New Test of the Lemons Model

[4] Anyaeche, C. O. 2007, The Automobile Assembly Plants in Nigeria,: A Failed Dream and The Way Forward:

[5] Research Manuscripts in the Department of Industrial and Production Engineering, University of Ibadan.

[6] Mishra, S. K. and Nardo, P (2009). Measuring uncertainties in composite indicators of sustainability, www.ingentaconnect.com/content/ind/ijetm/2009 assessed June, 2013.

[7] Mishra, S. K. 2007. Construction of an Index By Maximization of the Sum of its Absolute Correlation

[8] Coefficients With the Constituent Variables. SSRNhttp://ssrn.com/abstract=989088. Toyota Engineer training manual (2007). http://www.toyota.com

[9] Omoniyi, Ezekiel B., 2009, Composite Indices For Evaluation Of Used Vehicles In Nigeria, An MSc. Project (Unpublished) In The Department Of Industrial and Production Engineering University of Ibadan, Ibadan. Nigeria Automotive Manufacturer Association (NAMA), 2013 http://www.export.gov/comm_svc/eac., assessed February, 2013.

[10] TUV Reliability Report, 2013, Age of used Cars, www.anusedcar.com/index.php/tuv-report-yearage/2013-4- 5/307 assessed June, 2013. 